\title{
Explaining and forecasting interannual variability in the flow of the Nile River
}

\author{
M. S. Siam and E. A. B. Eltahir \\ Ralph M. Parsons Laboratory, Massachusetts Institute of Technology, 15 Vassar St., Cambridge, MA 02139, USA \\ Correspondence to: M. S. Siam (msiam@ mit.edu)
}

Received: 1 April 2014 - Published in Hydrol. Earth Syst. Sci. Discuss.: 14 May 2014

Revised: 26 January 2015 - Accepted: 2 February 2015 - Published: 3 March 2015

\begin{abstract}
This study analyzes extensive data sets collected during the twentieth century and defines four modes of natural variability in the flow of the Nile River, identifying a new significant potential for improving predictability of floods and droughts. Previous studies have identified a significant teleconnection between the Nile flow and the eastern Pacific Ocean. El Niño-Southern Oscillation (ENSO) explains about $25 \%$ of the interannual variability in the Nile flow. Here, this study identifies a region in the southern Indian Ocean, with a similarly strong teleconnection to the Nile flow. Sea surface temperature (SST) in the region $\left(50-80^{\circ} \mathrm{E}\right.$ and $\left.25-35^{\circ} \mathrm{S}\right)$ explains $28 \%$ of the interannual variability in the flow of the Nile River and, when combined with the ENSO index, the explained variability of the flow of the Nile River increases to $44 \%$. In addition, during those years with anomalous SST conditions in both oceans, this study estimates that indices of the SSTs in the Pacific and Indian oceans can collectively explain up to $84 \%$ of the interannual variability in the flow of the Nile. Building on these findings, this study uses the classical Bayesian theorem to develop a new hybrid forecasting algorithm that predicts the Nile flow based on global model predictions of indices of the SST in the eastern Pacific and southern Indian oceans.
\end{abstract}

\section{Introduction}

The Nile basin covers an area of $2.9 \times 10^{6} \mathrm{~km}^{2}$, which is approximately $10 \%$ of the African continent (Fig. 1). It has two main tributaries, the White Nile and the Blue Nile, which originate from the equatorial lakes and Ethiopian highlands, respectively. The upper Blue Nile (UBN) basin is the main source of water for the Nile River. It contributes approxi- mately $60 \%$ of the annual flow of the Nile and $80 \%$ of the total Nile flow that occurs between July and October at Dongola (Conway and Hulme, 1993) (Fig. 2). The UBN basin extends over an area of $175 \times 10^{3} \mathrm{~km}^{2}\left(7^{\circ} \mathrm{N}\right.$ to $12^{\circ} 5^{\prime} \mathrm{N}$ and from $34^{\circ} 5^{\prime} \mathrm{E}$ to $40^{\circ} \mathrm{E}$ ). The mean annual rainfall over this basin is $1200 \mathrm{~mm} \mathrm{yr}^{-1}$ (Conway and Hulme, 1993). Almost $60 \%$ of the annual rainfall over the UBN occurs during the summer between July and August, resulting in a largely predictable seasonal variability in the flow of the river.

The prediction of interannual variability in the flow of the Nile is rather challenging. Many studies investigated the teleconnections between the Ethiopian rainfall and the global sea surface temperature (SST) in order to find SST indices to use for Nile flow prediction (e.g., Eltahir, 1996; Abtew et al., 2009; Melesse et al., 2011). Eltahir (1996) showed that the SST anomalies over the tropical eastern Pacific Ocean explain $25 \%$ of the interannual variability of Nile flow for the period 1872-1972. ElSanabary et al. (2014) showed that the dominant frequencies of the Ethiopian rainfall ranged from 2 to 8 years and that the scale-averaged wavelet power of the SSTs over the eastern Pacific and southern Indian and Atlantic oceans can explain a significant fraction of the rainfall variability over Ethiopia using wavelet principal component analysis. These correlations between the Nile flow and SST indices were the basis for new forecast models that were proposed to predict the Nile flows. For example, Wang and Eltahir (1999) used a discriminant prediction approach to estimate the probabilities that the Nile flow will fall into prescribed categories. ElDaw et al. (2003) and Gissila et al. (2004) used SST over the Pacific, Indian and Atlantic oceans as predictors within a multiple linear regression model to predict the Nile flow. 


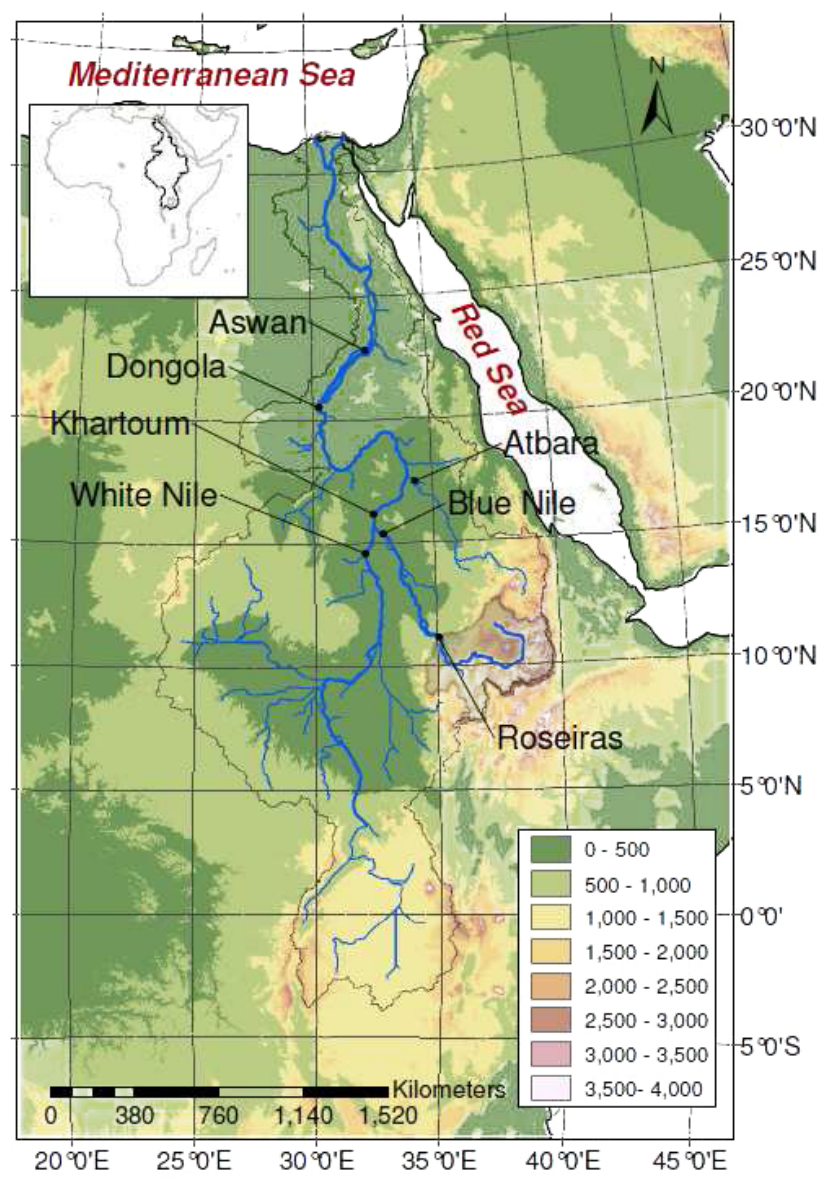

Figure 1. Topographic map of the Nile basin showing the outlet of the upper Blue Nile basin (shaded in gray) at Roseiras. The White and Blue Nile join together at Khartoum to form the main branch of the Nile that flows directly to Dongola in the north.

The mechanisms behind these teleconnections between the rainfall over Ethiopia and the global SSTs were examined in several studies (e.g., Beltrando and Camberlin, 1993). However, a clear distinction must be made between rainfall over the UBN basin in Ethiopia and rainfall over eastern Africa, defined as the region along the coast, east of the Ethiopian highlands (Fig. 1). The UBN basin has one rainy season (May to September) during which more than $80 \%$ of the rainfall occurs, while along the eastern coast of Africa and depending on the location from the Equator, the seasonal cycle of rainfall can have two rainy seasons (Black et al., 2003; Hastenrath et al., 2011). This pattern in the seasonal cycle of rainfall is related to the migration of the intertropical convergence zone (ITCZ) across the Equator. Camberlin (1995) showed that the rainfall over eastern Africa, including the UBN basin, is strongly coupled with the dynamics of the Indian monsoon. During strong Indian monsoon seasons, the sea level pressure over India decreases significantly, which enhances the pressure gradient between eastern Africa and India. As a result, westerly winds increase
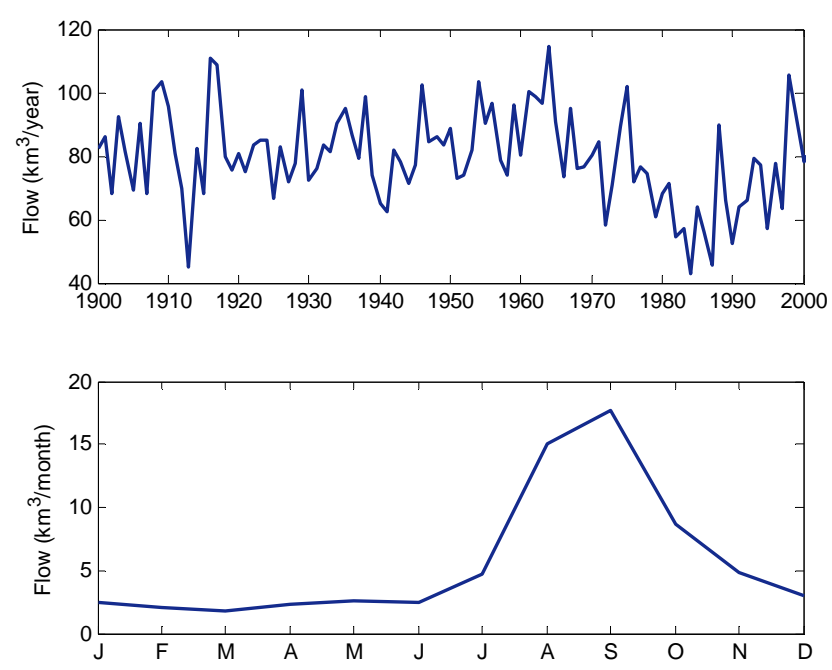

Figure 2. Annual Nile flow (top panel) and seasonal cycle (bottom panel) of the flow at Dongola for the period from 1900 to 2000 .

over eastern Africa and enhance transport moisture from the Congo basin to Ethiopia, Uganda and western Kenya. Giro et al. (2011) also showed that the warming over the Pacific Ocean, during El Niño events, reduces these westerly winds, which reduce the rainfall over eastern Africa. In addition, the monsoon circulation is weaker during El Niño events due to modulation of the Walker circulation and enhanced subsidence over the western Pacific and southern Asia; thus, the rainfall over Ethiopia decreases (Ju and Slingo, 1995; Kawamura, 1998; Shukla and Wallace, 1983; Soman and Slingo, 1997). The reduced Nile flows during El Niño events were also attributed to the enhanced tropical-scale subsidence that suppresses rainfall, as a consequence of the increased upwelling over the eastern Pacific Ocean (Amarasekera et al., 1996).

The physical mechanism of the teleconnection between the Nile flow and SSTs of the northern and middle Indian Ocean and ENSO is described in another paper by the authors (Siam et al., 2014). Nile flow is strongly modulated by ENSO through ocean currents. During El Niño events, the warm water travels from the Pacific Ocean to the Indian Ocean through the Indonesian through flow and advection by the Indian Equatorial Current (Tomczak and Godfrey, 1995). As a result, SSTs in the northern and middle Indian Ocean warm up following the warming of the tropical eastern Pacific, and force a gill-type circulation anomaly with enhanced westerly winds over the western Indian Ocean (Yang et al., 2007). The latter enhances the low-level divergence of air and moisture away from the upper Blue Nile, resulting in a reduction of rainfall over the basin. On the other hand, the warming over the southern Indian Ocean generates a cyclonic flow in the boundary layer, which reduces the cross-equatorial meridional transport of air and moisture towards the UBN basin, favoring a reduction in rainfall and river flows. The telecon- 


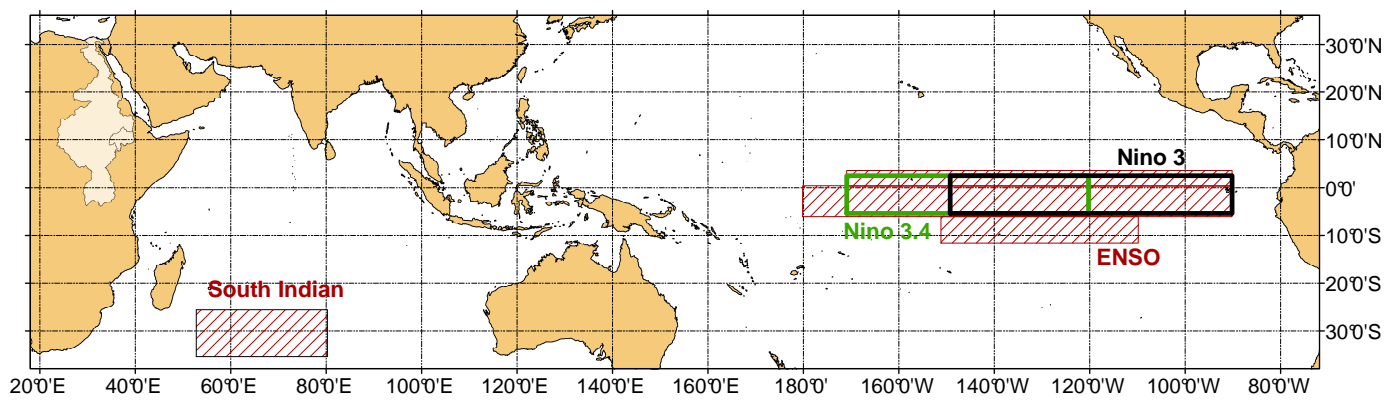

Figure 3. World map showing areas that cover the ENSO and northern and southern Indian Ocean SST indices. El Niño 3 and 3.4 are outlined in black and green, respectively. The whole Nile basin is outlined in black.

nections between the Pacific Ocean and the Nile basin and between the Indian Ocean and the Nile basin are reflected in different modes of observed natural variability in the flow of the Nile River, with important implications for the predictability of floods and droughts.

The objectives of the study are (i) to investigate the strength of the teleconnection between the Indian Ocean and the Nile basin and its role in explaining observed natural modes of variability in the flow of the Nile River, and (ii) to develop a new hybrid forecasting algorithm that can be used to predict the Nile flow based on indices of the SST in the eastern Pacific and southern Indian oceans.

\section{Data}

In this study, we use observed SSTs over the Indian and Pacific oceans from the monthly global (HadISST V1.1) data set on a $1^{\circ}$ latitude-longitude grid from 1900 to 2000 (Rayner et al., 2003). The monthly flows at Dongola from 1900 to 1984 were extracted from the Global River Discharge Database (RivDIS v1.1) (Vörösmarty et al., 1998) and from 1984 to 2000 through personal connection. The average monthly anomalies from September to November of the SSTs averaged over the eastern Pacific Ocean $\left(6-2^{\circ} \mathrm{N}, 170\right.$ $90^{\circ} \mathrm{W} ; 2^{\circ} \mathrm{N}-6^{\circ} \mathrm{S}, 180-90^{\circ} \mathrm{W}$; and $6-10^{\circ} \mathrm{S}, 150-110^{\circ} \mathrm{W}$ ) are used as an index of ENSO. This area has shown the highest correlation with the Nile flows, and it almost covers the same area as the Niño 3 and 3.4 indices (Trenberth, 1997).

\section{Relation between the variability in the flow of the Nile River, ENSO and the Indian Ocean SST}

Based on extensive correlation analysis of the Nile River flow at Dongola and the observed SST in the Indian Ocean, this study identifies a region over the southern Indian Ocean (50$80^{\circ} \mathrm{E}$ and $25-35^{\circ} \mathrm{S}$ ) (see Fig. 3) as the one with the highest correlation between SST and the Nile flow. This correlation is especially high for river flow (accumulated for July, August, September and October) and SST during the month of August. An earlier study by ElDaw et al. (2003) used SST indices over the Indian Ocean to predict the Nile flow; however, they focused on regions of the Indian Ocean that are different from the region that we use in defining the southern Indian Ocean (SIO) index. In other words, the region of the SIO was not used by ElDaw et al. (2003). Table 2 describes the regions of the Indian Ocean identified in both studies.

This study emphasizes that the proposed forecasting methodology for the Nile flow is motivated by the physical mechanisms proposed by Siam et al. (2014) and described in Sect. 1. In contrast, the forecasting approach of some of the previous studies was based on purely statistical correlations found between the Nile flow and SSTs globally.

Figure 4 shows the observed and simulated time series of the average July-to-October Nile flow at Dongola, which accounts for approximately $70 \%$ of the annual Nile flow. The Nile flow is predicted by three different linear regression models using either ENSO averaged from September to November (Fig. 4a) or SIO August (Fig. 4b) indices, or both (Fig. 4c) as covariates. It is clear from this figure that the addition of the SIO index increases the explained variability of the Nile flow to $44 \%$, compared to only $30 \%$ when the ENSO index is used alone. This indicates that the SIO index can explain almost $14 \%$ of the variability of the Nile flow that is independent of ENSO. The north and middle of the Indian Ocean have also exhibited a high correlation between their SST and the Nile flow. However, the additional variability explained by the SST over the northern and middle Indian Ocean, when combined with the ENSO index, is negligible (not shown here). This is mainly because the SSTs over the northern and middle Indian Ocean are dependent on ENSO, while the SST over the southern Indian Ocean (i.e., the SIO index) is not, as described in Sect. 1.

In further analysis, we define $\pm 0.5^{\circ} \mathrm{C}$ as the threshold between non-neutral and neutral years in the eastern Pacific Ocean, based on the ENSO index. This value is about twothirds of 1 standard deviation of the anomalies of the ENSO index. The same threshold has been used to identify nonneutral and neutral years using the El Niño 3.4 index, which is similar to our ENSO index (Trenberth, 1997). This indicates that if the ENSO index anomaly is greater than $0.5^{\circ} \mathrm{C}$ 

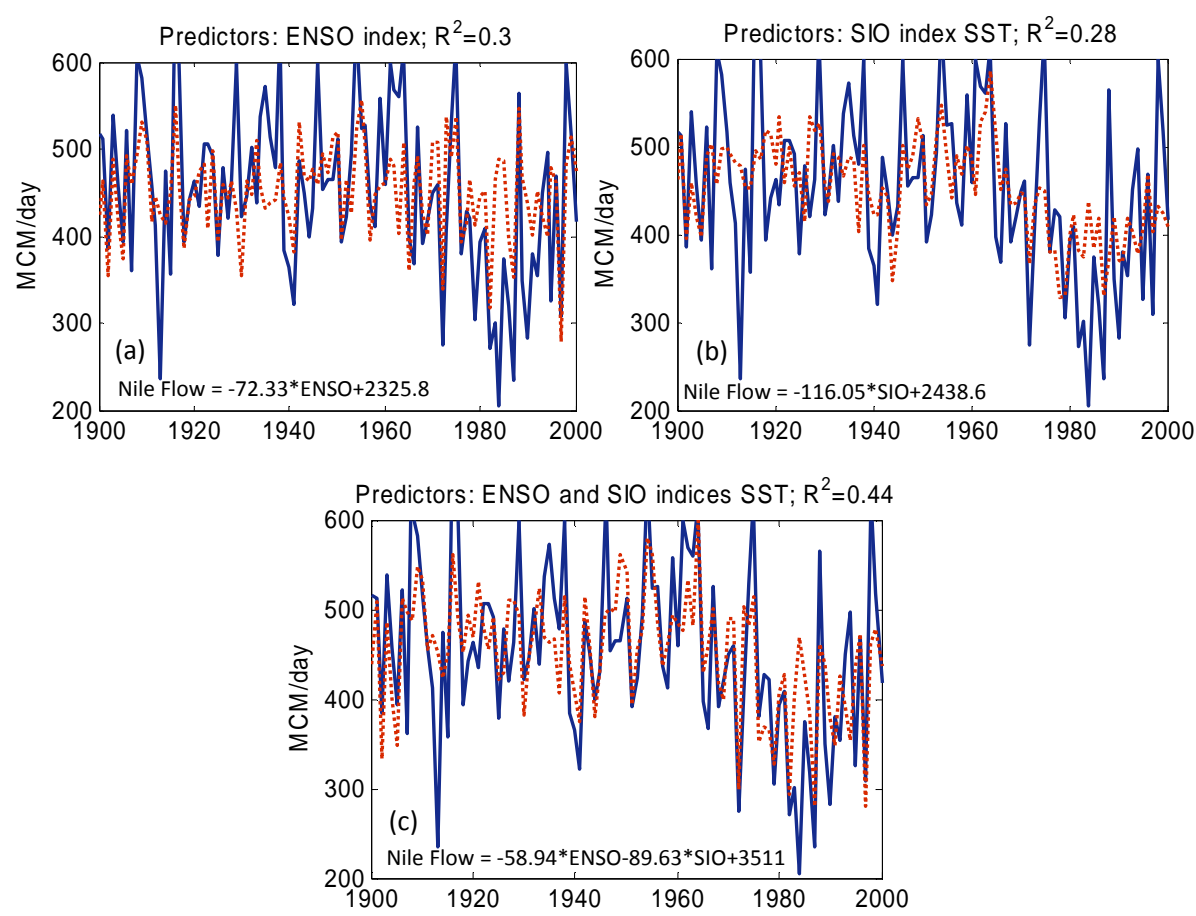

Figure 4. Observed (solid blue lines) and simulated (dashed red lines) average Nile flows in million cubic meters per day (MCM day ${ }^{-1}$ ) from July to October at Dongola using the (a) ENSO index, the (b) SIO index and the (c) ENSO and SIO indices as predictors for the period 1900 to 2000. The simulated flows are calculated based on the equations shown in each figure, in which the predictands are the average observed SSTs over the ENSO and SIO regions in degrees Celsius and the predictor is the average Nile flow from July to October in million cubic meters per day $\left(\mathrm{MCM}_{\mathrm{day}}{ }^{-1}\right)$.

or less than $-0.5^{\circ} \mathrm{C}$, it is considered a non-neutral condition; otherwise, it is considered a neutral condition. Similarly, a $\pm 0.3^{\circ} \mathrm{C}$ value is used as a threshold between non-neutral and neutral years in the southern Indian Ocean using the SIO index. This value is also about two-thirds of 1 standard deviation for the anomalies of the SSTs over this region. Thus, if both ENSO and SIO indices are used together, four different combinations can be defined based on these classifications. The first is when both ENSO and SIO indices are neutral ( 29 out of 100 events), the second is when both ENSO and SIO indices are non-neutral (19 out of 100 events), the third when SIO is non-neutral and ENSO is neutral (26 out of 100 events) and, finally, when SIO is neutral and ENSO is nonneutral (26 out of 100 events). Each of these combinations is considered a mode of natural variability in the flow of the Nile River. Then, the Nile flow is calculated as a predictand using multiple linear regression, with the ENSO and SIO indices of each mode as predictors.

Four different modes are identified for describing the natural variability in the flow of the Nile River and are summarized in Table 1. The ENSO and SIO indices do not explain a significant fraction of the interannual variability in the flow of river when they are both neutral (Fig. 5a). The variability of the Nile flow in such years can be regarded as a reflection of the chaotic interactions between the biosphere
Table 1. Summary of the coefficient of determination $\left(R^{2}\right)$ between the average Nile flow from July to October and different combinations of indices of ENSO and SIO.

\begin{tabular}{llccll}
\hline \multicolumn{2}{c}{ Mode } & ENSO & SIO & $\begin{array}{l}\text { ENSO, } \\
\text { SIO }\end{array}$ & $\begin{array}{l}\text { Number of } \\
\text { events } \\
\text { (observed } \\
\text { variance } \\
\text { of Nile flow })\end{array}$ \\
\hline Neutral & Neutral & 0.04 & 0.03 & 0.08 & $\begin{array}{l}29 \\
(6.76)\end{array}$ \\
\hline Neutral & Non-neutral & 0.05 & $0.28^{\mathrm{a}}$ & $0.31^{\mathrm{a}}$ & $\begin{array}{l}26 \\
(10.24)\end{array}$ \\
\hline Non-neutral & Neutral & $0.4^{\mathrm{a}}$ & 0.02 & $0.43^{\mathrm{a}}$ & $\begin{array}{l}26 \\
(5.8)\end{array}$ \\
\hline Non-neutral & Non-neutral & $0.64^{\mathrm{a}}$ & $0.6^{\mathrm{a}}$ & $0.84^{\mathrm{a}}$ & $\begin{array}{l}19 \\
(12.3)\end{array}$ \\
\hline
\end{tabular}

Note: the values between parentheses are for the observed variance of Nile flow of each mode in units of $\mathrm{MCM}^{2} \mathrm{day}^{-2}$. SIO: southern Indian Ocean SST index; ENSO: ENSO index. ${ }^{a}$ Values that are significant at the $1 \%$ significance level.

and atmosphere and within each of the two domains. For this mode, the predictability of the Nile flow is rather limited. The other two intermediate modes include non-neutral conditions in the eastern Pacific and neutral conditions in the southern Indian Ocean, or vice versa (Fig. $5 b$ and c). For 

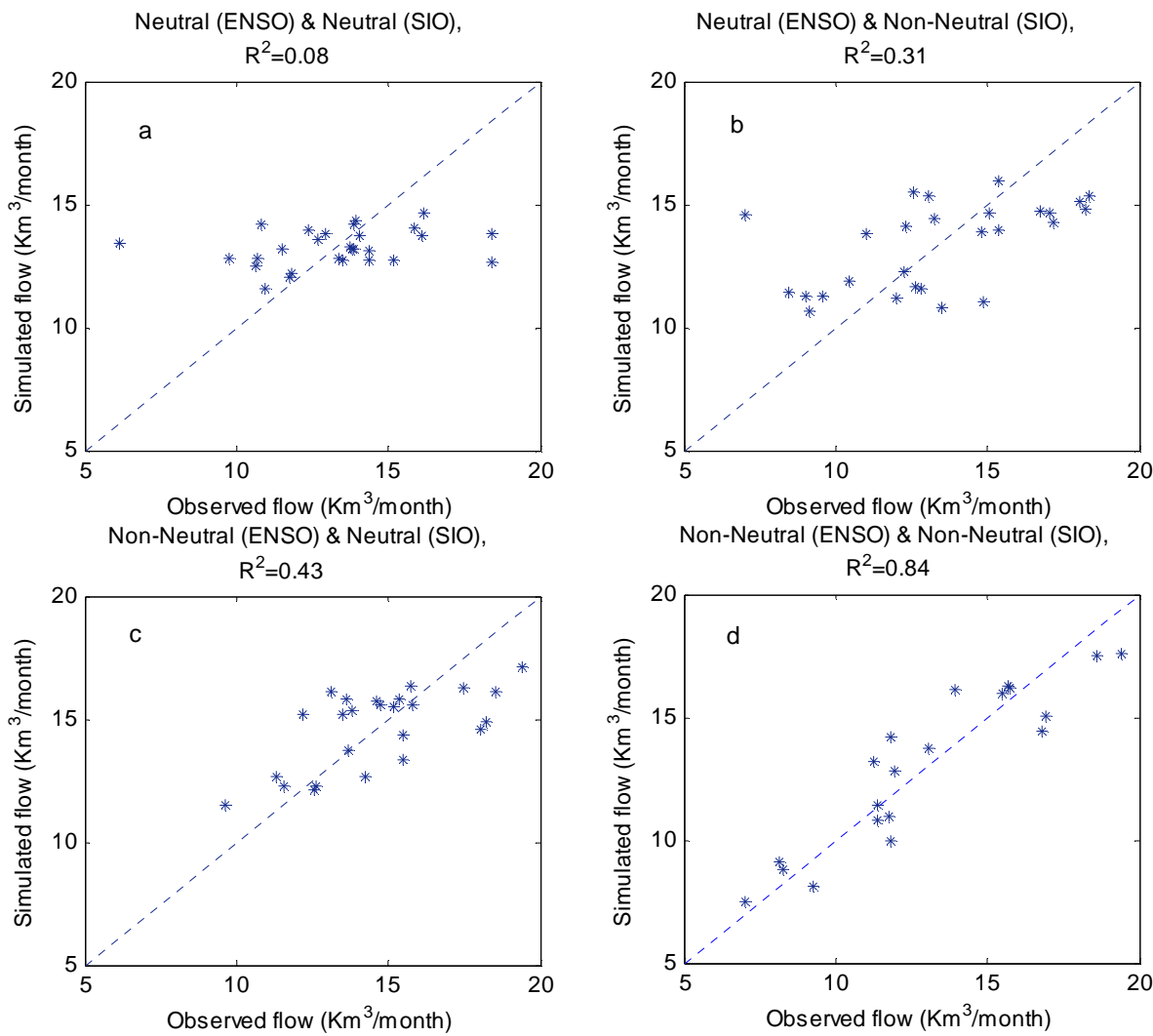

Figure 5. A comparison between the observed and simulated Nile flow showing the different modes of variability for the period from 1900 to 2000: (a) neutral ENSO (29 events) and SIO, (b) neutral ENSO and non-neutral SSTs in SIO (26 events), (c) non-neutral ENSO and neutral SSTs in SIO (26 events) and, finally, (d) non-neutral ENSO and non-neutral SSTs in SIO (19 events).

Table 2. Comparison between regions in the Indian Ocean used in ElDaw et al. (2003) and this study to predict the Nile flow.

\begin{tabular}{lll}
\hline Region & Location & Study \\
\hline 1 & $\left(35-44^{\circ} \mathrm{S}, 115-130^{\circ} \mathrm{E}\right)$ & \\
2 & $\left(0-7^{\circ} \mathrm{S}, 90-130^{\circ} \mathrm{E}\right)$ & ElDaw et al. (2003) \\
3 & $\left(35-44^{\circ} \mathrm{S}, 20-60^{\circ} \mathrm{E}\right)$ & \\
4 & $\left(10-20^{\circ} \mathrm{S}, 110-125^{\circ} \mathrm{E}\right)$ & \\
\hline 5 & $\left(50-80^{\circ} \mathrm{E}, 25-35^{\circ} \mathrm{S}\right)$ & This study \\
\hline
\end{tabular}

these two modes, a significant fraction (i.e., 31 and $43 \%$ ) of the variance describing interannual variability in the flow is explained. Hence, these modes point to a significant potential for predictability of the flow. Finally, indices of ENSO and SIO can explain $84 \%$ of the interannual variability in the Nile flow when non-neutral conditions are observed for both the eastern Pacific and southern Indian oceans (Fig. 5d). Therefore, the SIO index can be used to predict the flow together with the ENSO index, as collectively they can explain a significant fraction of the variability in the flow of the Nile River. This result indicates that, during years with anomalous SST conditions in both oceans, floods and droughts in the Nile River flow can be highly predictable, assuming accurate forecasts of those indices are available.

\section{A hybrid methodology for long-range prediction of the Nile flow}

A simple methodology is proposed to predict the Nile flow with a lead time of about a few months ( $\sim 3-6$ months). The forecast of global SST distribution based on dynamical models (e.g., NCEP coupled forecast system model version 2 (CFSv2); Saha et al., 2010, 2013) can be used together with the algorithm developed in this section to relate the Nile flow to the ENSO and SIO indices. The proposed method is shown in Fig. 6 and can be described in two main steps.

- Forecast of SST anomalies in the Indian Ocean and eastern Pacific Ocean using dynamical models of the coupled global ocean atmosphere system. Such forecasts are routinely issued by centers such as NCEP and ECMWF.

- Application of a forecast algorithm between the Nile flow (predictand) and forecasted SSTs in the Indian 


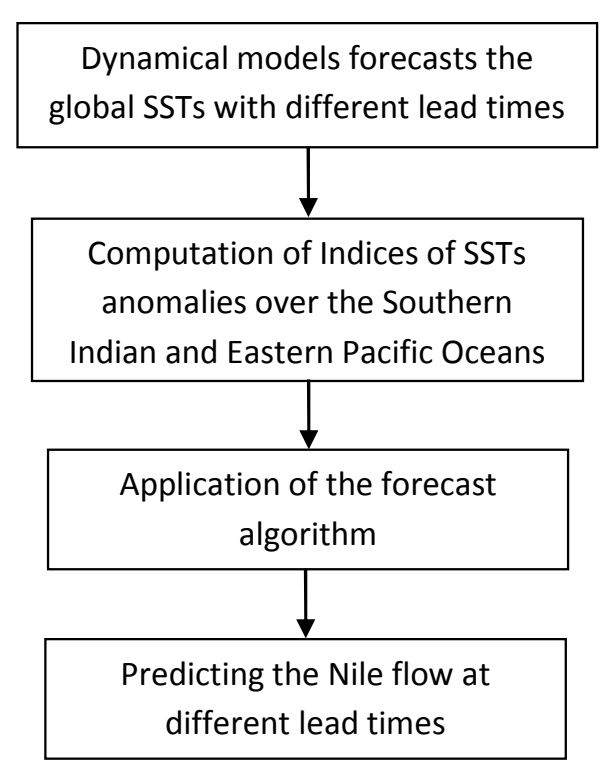

Figure 6. Schematic of the hybrid methodology for predicting the Nile flow using the SST forecasts of the dynamical models and the proposed forecast algorithm.

and eastern Pacific oceans (predictors) for the identified mode of variability.

In this paper, we focus on the second step of the proposed method: the development of the algorithm relating SSTs and the Nile flow. We develop the forecast algorithm using observed SSTs. We do not describe how this algorithm can be applied with forecasts of global SST distribution based on dynamical models, as this step is beyond the scope of this paper. However, we recognize that the overall accuracy of this method in predicting interannual variability of the Nile flow is dependent on the skill of global coupled models in forecasting the global SSTs (see the Appendix for information about forecasting models). Thus, the selection of the forecast model that predicts the SSTs is an important step to ensure the accuracy of the prediction of the Nile flow. As global coupled ocean-atmosphere models improve in their skill of forecasting global SSTs in the Pacific and Indian oceans, we expect that our ability to predict the interannual variability in the Nile flow will improve too. In addition, the accuracy in the prediction of the Nile flow on medium and short timescales (of weeks to 1 month) can be improved by adding other hydrological variables (e.g., rainfall and stream flow) over the basin, as demonstrated by Wang and Eltahir (1999).

The proposed method can be described as hybrid since it combines dynamical forecasts of global SSTs and statistical algorithms relating the Nile flow and the forecasted SSTs. The same method can also be described as hybrid since it combines information about SSTs from the Pacific and Indian oceans.
Here, we apply a discriminant approach that specifies the categoric probabilities of the predictand (Nile flow) according to the categories that the predictors (i.e., the ENSO and SIO indices) fall into. The annual Nile flow is divided into "low", "normal", and "high" categories. The boundaries of these categories are defined so that the number of points in each category is about one-third that of the data points (Fig. 7). On the other hand, the ENSO and SIO indices are divided into "cold", "normal" and "warm" categories. (The words "normal" and "neutral" are used to describe the same conditions.) The boundaries for the normal category are -0.5 and $0.5^{\circ} \mathrm{C}$ for the ENSO index and -0.3 and $0.3^{\circ} \mathrm{C}$ for the SIO index (Fig. 7). Any condition below the lower limit is considered "cold", and higher than the upper limit is considered "warm" for both indices.

The Bayesian theorem, described in many statistical books (e.g., Winkler 1972; West, 1989), states that the probability of occurrence of a specified flow category $\left(Q_{i}\right)$ and given two conditions $(A$ and $B)$ can be expressed as

$P\left(Q_{i} / A B\right)=\frac{P\left(B / Q_{i}, A\right) P\left(Q_{i} / A\right)}{P(B / A)}$,

where $P\left(Q_{i} / A\right)$ is the probability of event $Q_{i}$ given that event $A$ has occurred, and $P\left(Q_{i} / A B\right)$ is the probability of event $Q_{i}$ given that events $A$ and $B$ have occurred, and similarly for other shown probabilities. In addition, if the events $A$ and $B$ are independent, we can rewrite Eq. (1) as

$$
P\left(Q_{i} / A B\right)=\frac{P\left(B / Q_{i}\right) P\left(Q_{i} / A\right)}{\sum_{i=1}^{3} P\left(B / Q_{i}\right) P\left(Q_{i} / A\right)} .
$$

The advantage of assuming independence between $A$ and $B$ and using Eq. (2) is that it simplifies the calculation of $P\left(B / Q_{i}, A\right)$, since we do not have to split the data into a relatively large number of categories, which reduces the error due to the limitation of the data size (i.e. 100 years of data). The independence between the ENSO and SIO indices is a reasonable assumption, as the coefficient of determination between them is less than $6 \%$.

In order to evaluate the predictions of the Nile flow, we use a forecasting index (FI) defined by Wang and Eltahir (1999) as

$$
\begin{aligned}
& \mathrm{FP}(j)=\sum_{i=1}^{3} P_{\mathrm{r}}(i, j) P_{\mathrm{p}}(i, j), \\
& \mathrm{FI}=\frac{1}{n} \sum_{i=1}^{n} \operatorname{FP}(j),
\end{aligned}
$$

where $\operatorname{FP}(j)$ is the forecast probability in a certain year $(j)$ and the FI is the average of the FP over a certain period, $n$. The prior probability $P_{\mathrm{r}}(i, j)$ is calculated using Eq. (2) for a certain year $(j)$ and category $(i=1,2,3)$ and the posterior probability $P_{\mathrm{p}}(i, j)$ is defined as $[1,0,0]$ in a low flow 

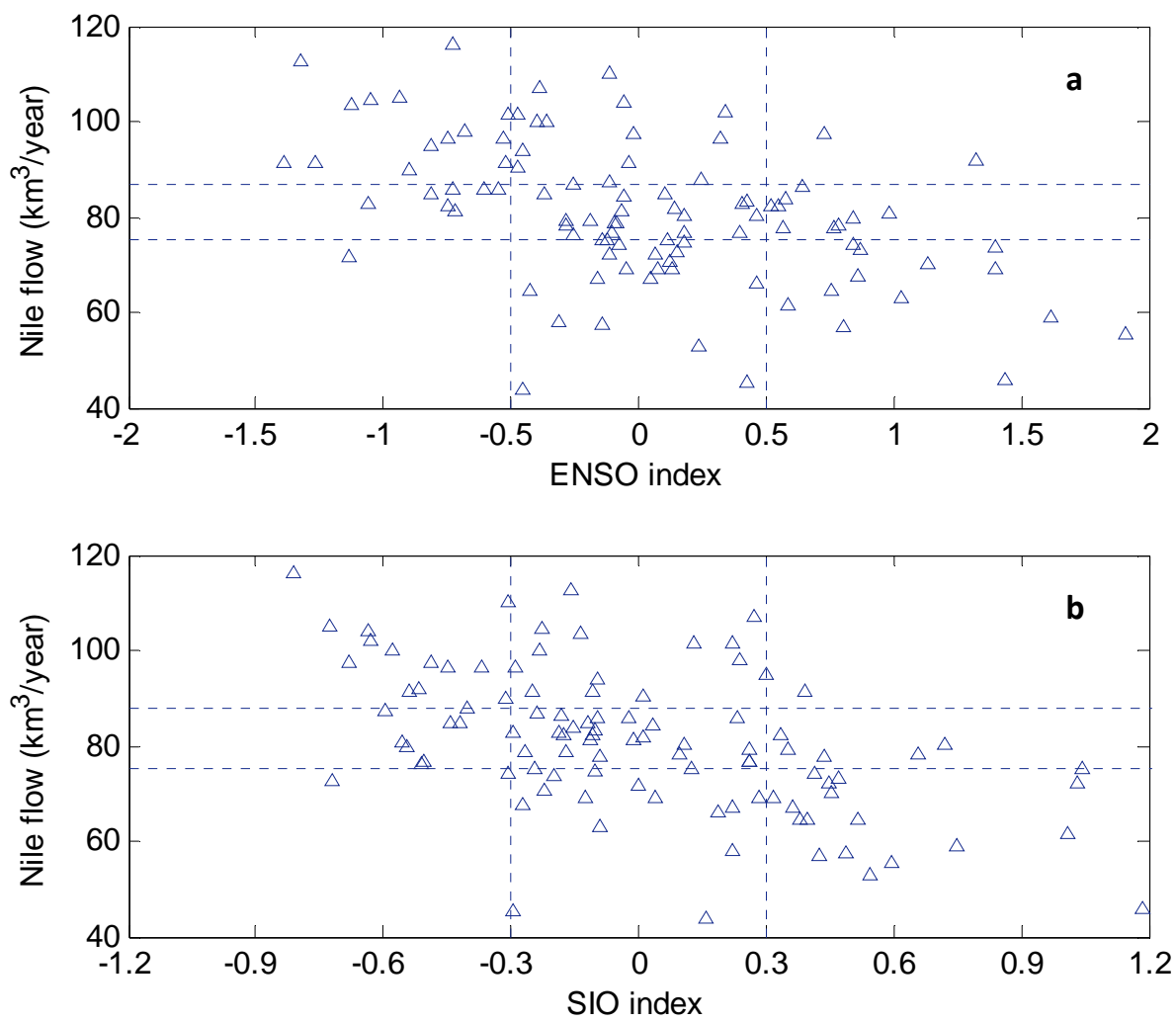

Figure 7. Relations between the annual Nile flow and different indices for the period (1900-2000): (a) ENSO and (b) SIO. The horizontal lines represent the boundaries for the "high", "normal" and "low" categories of the annual flow. The vertical lines represent the boundaries for the "warm", "normal", and "cold" conditions for the ENSO and SIO indices.

Table 3. Conditional probability of the Nile flow given SIO conditions.

\begin{tabular}{llcc}
\hline SIO & High & Nile flow \\
Warm & 0 & 0.25 & 0.75 \\
Normal & 0.23 & 0.39 & 0.39 \\
Cold & 0.57 & 0.26 & 0.17 \\
\hline
\end{tabular}

year, $[0,1,0]$ in a normal year, and $[0,0,1]$ in a high flow year. Hence, a larger FI indicates a higher accuracy of the forecast. The FI without any information about SST should be about one-third, as we have classified flow data into three categories, each with a similar number of data points.

The data are split into a calibration period (1900-1970) and a verification period (1970-2000). Tables 3 and 4 summarize the conditional probabilities of Nile flow given certain conditions of the SIO or ENSO index. It is shown that during warm and cold conditions of SIO, the probabilities are significantly higher for low and high Nile flow, respectively. The same is true for the ENSO, as was described originally by Eltahir (1996). Table 5 shows the probabilities that are conditioned on both SIO and ENSO, calculated using Eq. (2).
This table illustrates clearly how forecasts of the Nile flow can be improved by combining the two indices. For example, warm conditions in both oceans translate into $85 \%$ probability of low flow in the Nile, and an insignificant probability of high flow. On the other hand, cold conditions in both oceans translate into $83 \%$ probability of high flow in the Nile, and insignificant probability of low flow. Depending on the accuracy of the dynamical forecast models of global SSTs, such forecasts of the Nile flow can be issued with lead times of 6 months. At present, the Eastern Nile Regional Technical Office (ENTRO) issues operational forecasts of the Nile flow based on ENSO forecasts and the probability table described by Eltahir (1996) (similar to Table 4). We anticipate that use of Table 5 would represent a significant improvement in these operational forecasts.

The combined use of the ENSO and SIO indices significantly increased the FI to 0.5 (Fig. 8a). Comparison of Fig. $8 \mathrm{~b}$ and $\mathrm{c}$ illustrates that the SIO index alone has almost the same FI value as the ENSO index. Recall that, in the absence of any information about global SSTs, the FI should have a value of one-third. The deviations of the FI using the ENSO index alone (Fig. 8b) or the SIO index alone (Fig. 8c) from one-third are almost added together to create the deviation of the FI from the hybrid method from one-third 


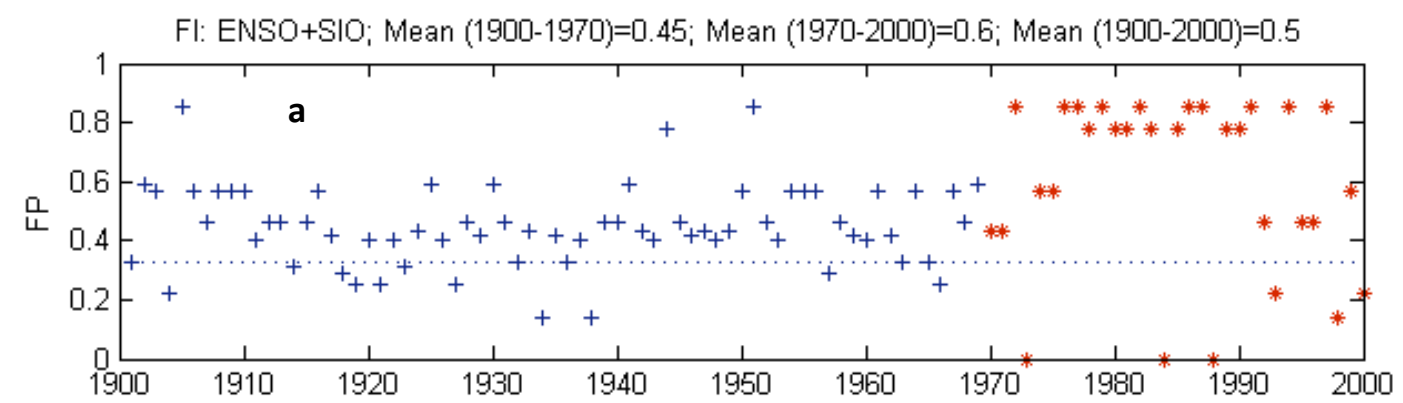

FI: ENSO; Mean (1900-1970)=0.37; Mean (1970-2000)=0.48; Mean (1900-2000) $=0.4$

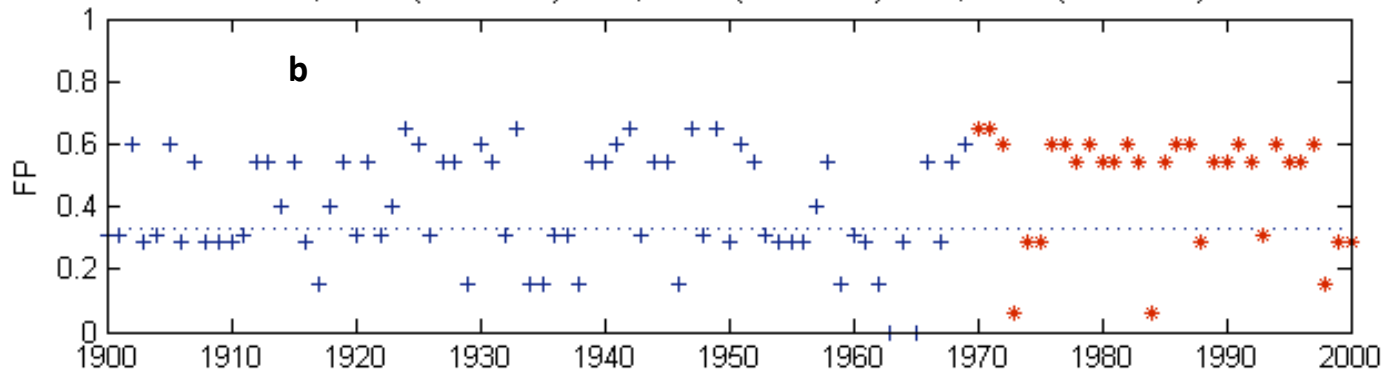

FI: SIO; Mean $(1900-1970)=0.37$; Mean $(1970-2000)=0.51$; Mean $(1900-2000)=0.41$

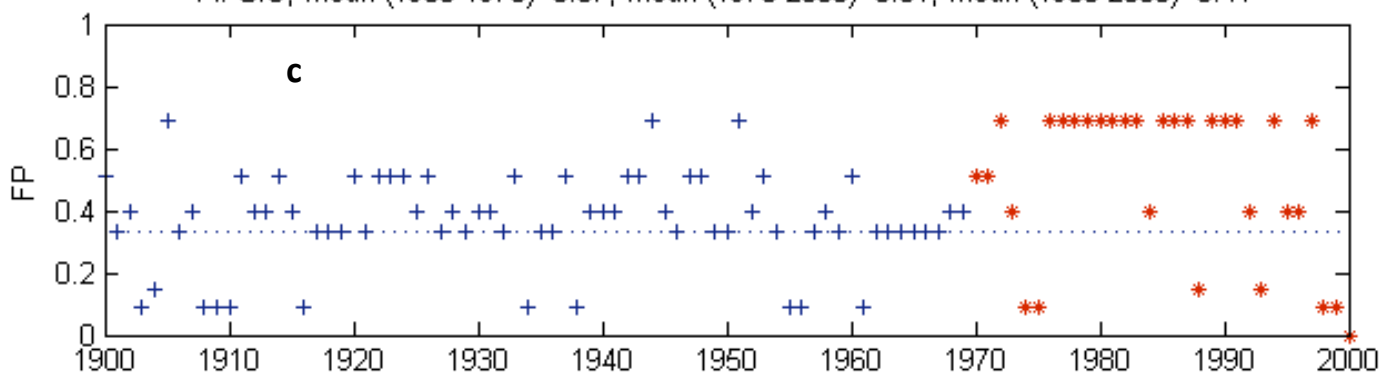

Figure 8. Time series of the forecast probability using different indices: (a) ENSO and SIO together, (b) ENSO, and (c) SIO. The period (1900-1970) is used for calculating the probabilities (shown in crosses) using Eq. (2) and 1970-2000 for validation (shown in stars).

Table 4. Conditional probability of the Nile flow given ENSO conditions.

\begin{tabular}{lccl}
\hline ENOSO & High & Nile flow & \\
& Normal & Low \\
\hline Warm & 0.15 & 0.31 & 0.54 \\
Normal & 0.22 & 0.38 & 0.41 \\
Cold & 0.68 & 0.32 & 0 \\
\hline
\end{tabular}

(Fig. 8a). Hence, the new SIO index plays a role independent of ENSO in shaping the interannual variability in the flow of the Nile River. Thus, by using these two indices, we explain a significant fraction of the interannual variability in the flow of the Nile River, and illustrate a significant potential for improving the Nile flow forecasts.
Table 5. Conditional probability of the Nile flow given SIO and ENS conditions.

\begin{tabular}{lllll}
\hline SIO & Nile & \multicolumn{3}{c}{ ENSO } \\
\cline { 3 - 5 } & flow & Warm & Normal & Cold \\
\hline SIO warm & High & 0 & 0 & 0 \\
& Normal & 0.15 & 0.22 & 1 \\
& Low & 0.85 & 0.78 & 0 \\
\hline SIO normal & High & 0.1 & 0.14 & 0.57 \\
& Normal & 0.31 & 0.4 & 0.43 \\
& Low & 0.59 & 0.46 & 0 \\
\hline SIO cold & High & 0.33 & 0.42 & 0.83 \\
& Normal & 0.29 & 0.33 & 0.17 \\
& Low & 0.37 & 0.25 & 0
\end{tabular}




\section{Conclusions}

- In this paper, we document that the SSTs in the eastern Pacific and Indian oceans play a significant role in shaping the natural interannual variability in the flow of the Nile River. Previous studies have identified a significant teleconnection between the Nile flow and the eastern Pacific Ocean. El Niño-Southern Oscillation (ENSO) explains about $25 \%$ of the interannual variability in the Nile flow. Here, this study identifies a region in the southern Indian Ocean with a similarly strong teleconnection to the Nile flow. Sea surface temperature (SST) in the region $\left(50-80^{\circ} \mathrm{E}\right.$ and $\left.25-35^{\circ} \mathrm{S}\right)$ explains $28 \%$ of the interannual variability in the Nile flow.

- In addition, four different modes of natural variability in the Nile flow are identified, and it is shown that during non-neutral conditions in both the Pacific and Indian oceans, the Nile flow is highly predictable using global SST information. During those years with anomalous SST conditions in both oceans, this study estimates that indices of the SSTs in the Pacific and Indian oceans can collectively explain up to $84 \%$ of the interannual variability in the flow of Nile. The estimated relationships between the Nile flow and these indices allow for accurate prediction of the Nile floods and droughts using observed or forecasted conditions of the SSTs in the two oceans.
- This study uses the classical Bayesian theorem to develop a new hybrid forecasting algorithm that predicts the Nile flow based on indices of the SST in the eastern Pacific and southern Indian oceans. Warm conditions in both oceans translate into $85 \%$ probability of low flow in the Nile, and insignificant probability of high flow. On the other hand, cold conditions in both oceans translate into $83 \%$ probability of high flow in the Nile, and insignificant probability of low flow. Applications of the proposed hybrid forecast method should improve predictions of the interannual variability in the Nile flow, adding a new tool for better management of the water resources of the Nile basin.

The proposed forecasting methodology is indeed dependent on the accuracy of the global SST forecasts from global dynamical models. The accuracy of these forecasts is likely to improve as the models are tested and developed further. However, in this paper, we test the proposed forecasting algorithm using observed SSTs. Such a test describes an upper limit of the skill of the proposed algorithm. The assessment of the same methodology using indices of SST forecasted by global dynamical models will be addressed in future work. 
1190 M. S. Siam and E. A. B. Eltahir: Explaining and forecasting interannual variability in the flow of the Nile River Appendix A: Forecast models of sea surface temperature

Table A1. Summary of some available forecast models of the sea surface temperature.

\begin{tabular}{|c|c|c|c|c|c|c|}
\hline Model & $\begin{array}{l}\text { Type of } \\
\text { model }\end{array}$ & Agency & Domain & $\begin{array}{r}\text { Lead time } \\
\text { (up to } \\
\text { months) }\end{array}$ & $\begin{array}{r}\text { Resolution } \\
(\mathrm{km})\end{array}$ & Reference \\
\hline NCEP-CFS V2 & Dynamical & $\begin{array}{l}\text { National Centers for Environmental } \\
\text { Prediction (NCEP) }\end{array}$ & Global & 8 & 200 & Saha et al. (2010) \\
\hline NASA-GMAO & Dynamical & $\begin{array}{l}\text { NASA Goddard Space Flight Center Global } \\
\text { Modeling and Assimilation Office }\end{array}$ & Global & 12 & 200 & Bacmeister et al. (2000) \\
\hline ECMWF-System 4 & Dynamical & $\begin{array}{l}\text { European Centre for Medium-Range } \\
\text { Weather Forecasts }\end{array}$ & Global & 4 & 70 & Molteni et al. (2011) \\
\hline UKMO-GCM & Dynamical & United Kingdom Met Office & Global & 6 & 150 & Graham et al. (2005) \\
\hline NOAA-CDC & Statistical & $\begin{array}{l}\text { National Oceanic and Atmospheric } \\
\text { Administration Climate Diagnostic Center }\end{array}$ & Global & 12 & - & Penland and Matrosova (1998) \\
\hline CPC-Markov & Statistical & $\begin{array}{l}\text { National Centers for Environmental Prediction } \\
\text { Climate Prediction Center }\end{array}$ & $\begin{array}{l}\text { Niño } 3 \text { and } \\
\text { Niño } 3.4\end{array}$ & 8 & - & Xue et al. (2000) \\
\hline
\end{tabular}


Edited by: T. Kjeldsen

\section{References}

Abtew, W., Melesse, A. M., and Dessalegne, T.: El Niño Southern Oscillation link to the Blue Nile River Basin hydrology, Hydrol. Process., 23, 3653-3660, doi:10.1002/hyp.7367, 2009.

Amarasekera, K. N., Lee, R. F., Williams, E. R., and Eltahir, E. A. B.: ENSO and the natural variability in the flow of tropical rivers, J. Hydrol., 200, 24-39, 1996.

Bacmeister, J. T., Pegion, P. J., Schubert, S. D., and Suarez, M. J.: An atlas of seasonal means simulated by the NSIPP 1 atmospheric GCM, NASA Tech. Memo. 104606, Vol. 17, Goddard Space Flight Center, Greenbelt, 194 pp., 2000.

Beltrando, G. and Camberlin, P.: Interannual variability of rainfall in Eastern Horn of Africa and indicators of atmospheric circulation, Int. J. Climatol., 13, 533-546, 1993.

Black, E., Slingo, J., and Sperber, K. R.: An observational study of the relationship between excessively strong short rains in coastal East Africa and Indian Ocean SST, Mon. Weather Rev., 31, 7494, 2003.

Camberlin, P.: June-September rainfall in North-Eastern Africa and atmospheric signals over the tropics: a zonal perspective, Int. J. Climatol., 15, 773-783, 1995.

Conway, D. and Hulme, M.: Recent Fluctuations in precipitation and runoff over the Nile subbasins and their impact on Main Nile discharge, Climatic Change, 25, 127-151, 1993.

ElDaw, A., Salas, J. D., and Garcia, L. A.: Long Range Forecasting of the Nile River Flows Using Climate Forcing, J. Appl. Meteorol., 42, 890-904, 2003.

ElSanabary, M. H., Gan, T. Y., and Mwale, D.: Application of wavelet empirical orthogonal function analysis to investigate the nonstationary character of Ethiopian rainfall and its teleconnection to nonstationary global Sea Surface Temperature variations for 1900-1998, Int. J. Climatol., 34, 1798-1813, doi:10.1002/joc.3802, 2014.

Eltahir, E. A. B.: ElNino and the natural variability in the flow of the Nile river, Water Resour. Res., 32, 131-137, 1996.

Giro, D., Grimes, D., and Black, E.: Teleconnections between Ethiopian summer rainfll and sea surface temperature: part I Observation and Modeling, Clim. Dynam., 37, 103-199, 2011.

Gissila, T., Black, E., Grimes, D. I. F., and Slingo, J. M.: Seasonal forecasting of the Ethiopian Summer rains, Int. J. Climatol., 24, 1345-1358, 2004.

Graham, R., Gordon, M., McLean, P. J., Ineson, S., Huddleston, M. R., Davey, M. K., Brookshaw, A., and Barnes, R. T. H.: A performance comparison of coupled and uncoupled versions of the Met Office seasonal prediction general circulation model, Tellus A, 57, 320-339, 2005.

Hastenrath, S., Polzin, D., and Mutai, C.: Circulation Mechanisms of Kenya Rainfall Anomalies, J. Climate, 24, 404-412, 2011.

Ju, J. and Slingo, J. M.: The Asian summer monsoon and ENSO, Q. J. Roy. Meteorol. Soc., 121, 1133-1168, 1995.

Kawamura, R.: A possible mechanism of the Asian summer monsoon-ENSO coupling, J. Meteorol. Soc. Jpn., 76, 10091027, 1998.

Melesse, A., Abtew, W., Setegn, S. G., and Desalegn, T.: Hydrological Variability and Climate of the Upper Blue Nile River Basin, in: Nile River Basin: Hydrology, Climate and Water Use, 1st Edn., edited by: Melesse, A. M., Springer, New York, USA, 3-37, doi:10.1007/978-94-007-0689-7_1, 2011.

Molteni, F., Stockdale, T., Balmaseda, M., Balsamo, G., Buizza, R., Ferranti, L., Magnusson, L., Mogensen, K., Palmer, T., and Vitart, F.: The new ECMWF seasonal forecast system (System 4), ECMWF Research Department Technical Memorandum no. 656, ECMWF, Reading, UK, 51 pp., 2011.

Penland, C. and Matrosova, L.: Prediction of Tropical Atlantic Sea Surface Temperatures Using Linear Inverse Modeling, J. Climate, 11, 483-496, 1998.

Rayner, N. A., Parker, D. E., Horton, E. B., Folland, C. K., Alexander, L. V., Rowell, D. P., Kent, E. C., and Kaplan, A.: Global analyses of sea surface temperature, sea ice, and night marine air temperature since the late nineteenth century, J. Geophys. Res., 108, 4407, doi:10.1029/2002JD002670, 2003.

Saha, S., Moorthi, S., Pan, H.-L., Wu, X., Wang, J., Nadiga, S., Tripp, P., Kistler, R., Woollen, J., Behringer, D., Liu, H., Stokes, D., Grumbine, R., Gayno, G., Wang, J., Hou, Y.-T., Chuang, H.Y., Juang, H.-M. H., Sela, J., Iredell, M., Treadon, R., Kleist, D., Van Delst, P., Keyser, D., Derber, J., Ek, M., Meng, J., Wei, H., Yang, R., Lord, S., van den Dool, H., Kumar, A., Wang, W., Long, C., Chelliah, M., Xue, Y., Huang, B., Schemm, J.-K., Ebisuzaki, W., Lin, R., Xie, P., Chen, M., Zhou, S., Higgins, W., Zou, C.-Z., Liu, Q., Chen, Y., Han, Y., Cucurull, L., Reynolds, R. W., Rutledge, G., and Goldberg, M.: The NCEP Climate Forecast System Reanalysis, B. Am. Meteorol. Soc., 91, 1015-1057, doi:10.1175/2010BAMS3001.1, 2010.

Saha, S., Moorthi, S., Wu, X., Wang, J., Nadiga, S., Tripp, P., Pan, H.-L., Behringer, D., Hou, Y.-T., Chuang, H.-Y., Iredell, M., Ek, M., Meng, J., Yang, R., van den Dool, H., Zhang, Q., Wang, W., and Chen, M.: The NCEP Climate Forecast System Version 2, J. Climate, 27, 2185-2208, 2013.

Shukla, J. and Wallace, J. M.: Numerical simulation of the atmospheric response to equatorial Pacific sea surface temperature anomalies, J. Atmos. Sci., 40, 1613-1630, 1983.

Siam, M. S., Wang, G., Estelle, M. E., and Eltahir, E. A. B.: Role of the Indian Ocean Sea Surface Temperature in shaping natural variability in the flow of the Nile River, Clim. Dynam., 43, 10111023, 2014.

Soman, M. K. and Slingo, J.: Sensitivity of the Asian summer monsoon to aspects of sea-surface-temperature anomalies in the tropical pacific ocean, Q. J. Roy. Meteorol. Soc., 123, 309-336, 1997.

Tomczak, M. and Godfrey, J. S.: Regional oceanography: an introduction, Pregamon, London, 1995.

Trenberth, K. E.: The Definition of El Niño, B. Am. Meteorol. Soc., 78, 2771-2777, 1997

Vörösmarty, C. J., Fekete, B., and Tucker, B. A.: River discharge database, Version 1.1 (RivDIS v 1.0 supplement), available through the institute for the study of earth, oceans and space University of New Hampshire, Durham, NH, USA, 1998.

Wang, G. and Eltahir, E. A. B.: Use of ENSO information in Medium and Long Range Forecasting of the Nile Floods, J. Climate, 12, 1726-1737, 1999.

West, M.: Bayesian Forecasting and Dynamic Models, Springer, New York, 704 pp., 1989.

Winkler, R.: An introduction to Bayesian inference and Decision, Holt, Rinchart and Winstoon, New York, 563 pp., 1972. 
1192 M. S. Siam and E. A. B. Eltahir: Explaining and forecasting interannual variability in the flow of the Nile River

Xue, Y., Leetmaa, A., and Ji, M.: ENSO prediction with Markov model: The impact of sea level, J. Climate, 13, 849-871, 2000.
Yang, J., Liu, Q., Xie, S.-P., Liu, Z., and Wu, L.: Impact of the Indian Ocean SST basin mode on the Asian summer monsoon, Geophys. Res. Lett., 34, L02708, doi:10.1029/2006GL028571, 2007. 